\title{
Step-free railway station access in the UK: the value of inclusive design
}

\author{
Antony Swift ${ }^{1}$, Long Cheng ${ }^{2^{*}}$ (D), Becky P. Y. Loo ${ }^{3}$, Mengqiu Cao ${ }^{4,5}$ and Frank Witlox 2,6
}

\begin{abstract}
Background: Despite substantial investment in step-free access at UK railway stations, persons with reduced mobility (PRMs) continue to travel less than their able-bodied counterparts and little is known about the value of step-free access. This research examines the benefits of step-free access and its relationship with rail usage among PRMs, and the wider benefits of railway station accessibility.

Methods: These issues are explored through a mixed methods approach. Semi-structured interviews with ten key organisations were undertaken, as was an analysis of Senior/Disabled Persons Railcard data from 17 railway stations in Buckinghamshire, each with varying levels of step-free accessibility.

Results: The results show that the benefits of step-free access extend beyond benefits at the individual level typically associated with those limited to PRMs, and demonstrate the potential to positively affect the society at large economically, environmentally, and socially. The findings also show a positive correlation between the level of step-free accessibility at a railway station and the percentage of PRMs using it.

Conclusions: This research argues that government and interested stakeholders should commit to expanding the number and coverage of step-free stations throughout the UK. They should ensure that the appraisal process for investment in step-free accessibility appropriately captures both user and non-user benefits.
\end{abstract}

Keywords: Older and disabled people, Railway station, Inclusive design, Accessibility, Transport equity, United Kingdom

\section{Introduction}

The mobility needs of older and disabled people are too often overlooked in transport planning, and they travel significantly less than their able-bodied counterparts $[7,26,34,35]$. This is most notably the case in the rail industry, where the divergence between the numbers of persons with reduced mobility (PRMs) using surface rail or the London Underground and people who have no mobility impairment is the greatest [14]. According to the National Travel Survey [28], people without mobility difficulty are almost four times more likely to use surface rail than PRMs; this imbalance is even greater in the case of the London Underground, which people without mobility difficulty are ten times more likely to use than PRMs (Fig. 1). PRMs

\footnotetext{
* Correspondence: long.cheng@ugent.be

${ }^{2}$ Department of Geography, Ghent University, Ghent, Belgium

Full list of author information is available at the end of the article
}

depend heavily on taxis/minicabs and cars/vans as passengers. These modes of transport are much more expensive and carbon intensive than rail transport. Based on Maslow's hierarchy of transit needs, proposed by Allen et al. [2], accessibility is one of the most important indicators that can be used to measure the functional attributes of a public transport system. It is also one of the most important drivers throughout a traveller's whole journey $[8,38]$. Accessibility in this research is based on the notion of universal or inclusive design, which is concerned with removing barriers and opening up opportunities for all people irrespective of their abilities. The focus is on the ease to use transport systems. In recent years, the transport profession has seen a paradigm shift in the importance placed on delivering an inclusive and accessible public transport system. Launched in 2006, the Access for All (AfA) programme has been the Government and railway industry's flagship programme to provide obstacle-free, 


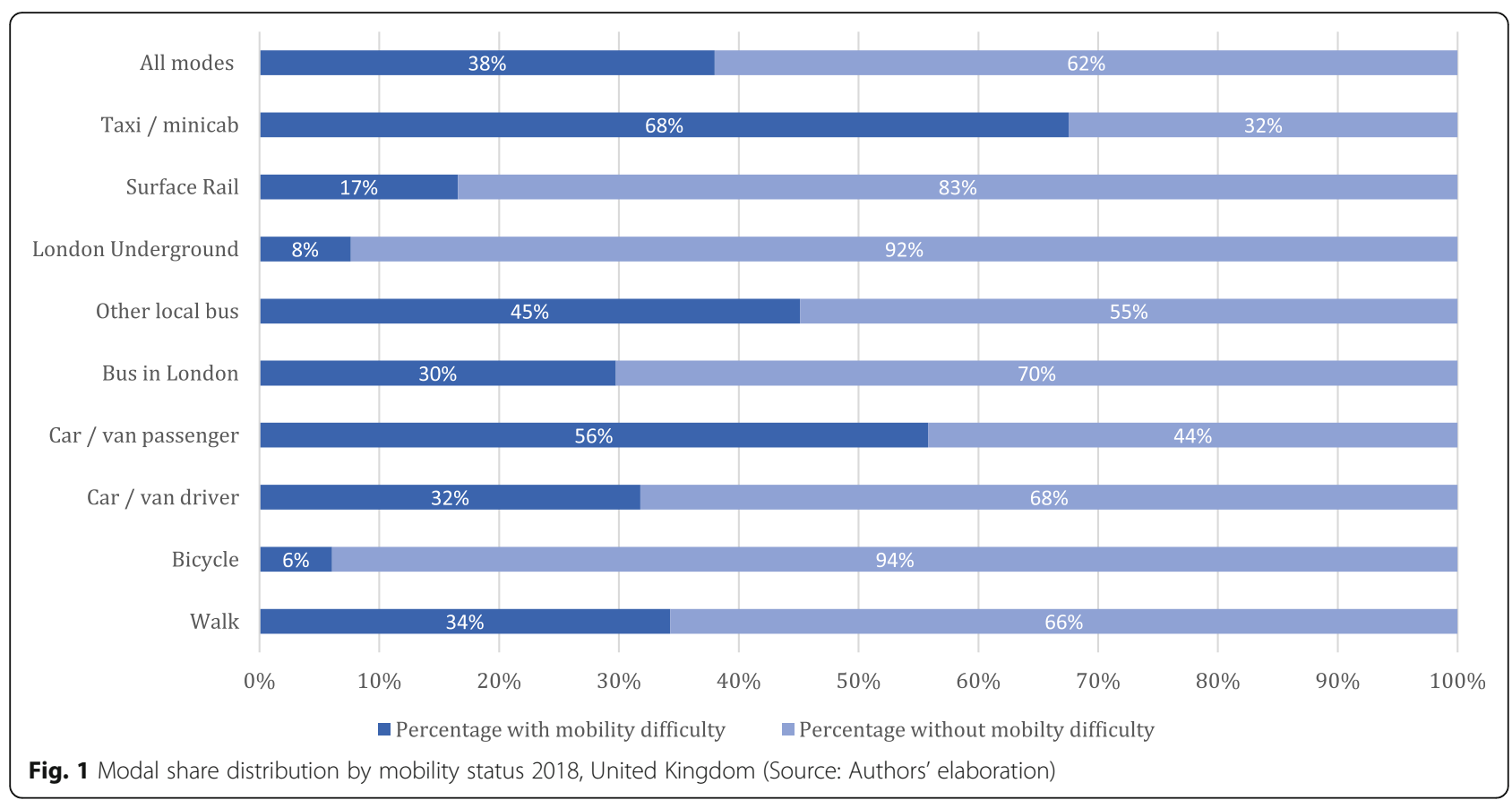

accessible routes to and between platforms in the UK. This investment in step-free access is intended to make it easier for PRMs to use the railway to visit friends, access amenities or travel to work [29].

AfA is funded by the Department for Transport (DfT) and delivered by Network Rail (NR). To date, $£ 500$ million has been invested to deliver accessible routes, including step-free access, at over 200 stations, with 1500 stations benefitting from smaller-scale improvements. The Government's Inclusive Transport Strategy [11] set out plans to make up to a further $£ 300$ million available to extend the programme until 2024. By this point, the Government's expenditure on accessible railway stations will have totalled approximately one billion pounds. Ordinarily, this amount of transport infrastructure investment is subject to the DfT's transport appraisal guidance criteria before funding is agreed [12]. This process requires sponsoring organisations to prepare a business case that sets out robust evidence on the case for change. Scheme promoters must also provide assurances on how they will measure and monitor the realisation of benefits achieved from the intervention over a set appraisal period. By contrast, investment in step-free access is not subject to these appraisal requirements.

Despite the significant levels of investment at railway stations across the country, there has been little research to ascertain the value of step-free access. Specifically, two gaps in the existing knowledge have been identified: (i) what are the benefits accrued from the step-free access scheme? and (ii) what is the relationship between step-free access and travel by PRMs? Maintaining the status-quo without empirical evidence may potentially undervalue the significance of accessibility investment. Therefore, the overall aim of this study is to advance the understanding of the value step-free access has at UK railway stations.

The rest of the paper is divided into four sections. Section 2 reviews the existing literature on the benefits of inclusive design at railway stations. This is followed by Section 3 which describes the semi-structured interviews and the railway station usage data that was used for analysis. Section 4 discusses the results of the analysis regarding the benefits of step-free access and the relationship between step-free access and travel by PRMs. Section 5 concludes the study by summarising the main findings and suggesting policy implications.

\section{Literature review}

The rail system can act as a barrier for PRMs in terms of accessing social and employment opportunities. At worst, inaccessible journeys by rail can result in a loss of social independence. This is exacerbated by economic hardship endured by an overreliance on more expensive modes of travel, such as cars or taxis $[6,10,21,39]$. In 2017, the DfT sought feedback on a range of proposals to improve the travel experience of PRMs. Feedback was requested on 48 proposals that sought to address a range of transport accessibility issues, including the blue badge scheme, ${ }^{1}$

\footnotetext{
${ }^{1}$ The blue badge scheme aims to assist PRMs to more easily access public transport by allowing them to park close to where they need to get to.
} 
concessionary bus fares and tactile paving [1]. The consultation attracted over 1000 responses, and the policy that received the most comments was the roll-out of station accessibility improvements and the delivery of the AfA programme [13]. Jones and Jain [24] echoed this finding by claiming that railway accessibility is a significant issue, and suggesting that there is a correlation between lower frequency usage of rail travel by disabled people and railways being the least accessible mode of transport.

Boarding and alighting barriers constitute a major challenge for PRMs when travelling by train. Most of the UK's rail system was constructed by private companies prior to nationalisation in 1948. Each part of the railway was built to its own standards, meaning that for most of the twentieth century, there has been no standardisation with regard to the height of platforms or the width of the trains that stop at them. As a result, the horizontal and vertical gaps between the train and platform cause problems for PRMs [18]. Consequently, even if routes from station entrances, through the concourse and to the platform are accessible, the gap between the platform edge and the train remains a major accessibility and mobility barrier for those using electronic or manual wheelchairs [20]. As of 2014, the relevant standard has specified a platform height of $915 \mathrm{~mm}$ above the height of the rails and an offset (the horizontal distance between the rails and platform edge) of $730 \mathrm{~mm}$ [33]. However, only $7 \%$ of stations in the UK meet both the height and offset specifications [23].

The role of transport in enabling new travel opportunities should serve to unlock the potential contribution that PRMs can make to society. Research has shown that a $10 \%$ rise in the employment rate amongst disabled adults could contribute an extra $£ 12$ billion to the Exchequer by 2030 [1]. The railway could become a key enabler in realising this potential. The demand to develop and adapt the built environment to accommodate the needs of PRMs should be driven by the social benefits that will accrue from this, in addition to a sense of equity. For the rail sector, traditional methods of evaluation have not been overly successful in taking nontransport related economic benefits into account $[4,17$, 36]. Consequently, the wider benefits displaced or lost by the existing appraisal process may result in the economic, social or environmental benefits generated by step-free access being undervalued.

In response to the fact that accessibility benefits are seldom considered in business case development for railway interventions, Karekla et al. [25] undertook conceptual research into the economic case of raising an entire platform and increasing the doorway width of the trains serving it. Their results show that inclusive design can lead to a reduction in operating costs and faster journey times for passengers due to smoother boarding and alighting, thus making the project economically viable and demonstrating a positive benefit-cost ratio. In order to analyse the impact and monetary benefits of inclusive design at railway stations, the DfT commissioned a study to assess the benefits of accessible pedestrian routes at railway stations, based on a small sample of railway stations that offer step-free access [16]. The economic appraisal uncovered a number of potential benefits resulting from improved station accessibility. In general terms, step-free access helps three sets of people: (i) existing users due to obstacle-free routes and better signage, etc.; (ii) new users who are attracted to the station by these improvements; and (iii) non-users, i.e. people who do not change their behaviour but benefit from a reduction in car trips - e.g. reduced accident and emission costs and decongestion benefits for other road users. The research by Duckenfield [16] provides the only evidence-led proxy of the benefits and impacts of step-free access. However, it is significantly constrained by its extremely small sample size, comprising only six stations, with each station being managed by a mixture of different train operating companies (TOCs). Each TOC has a different approach to marketing and promoting the station accessibility improvements to their customers which influences their relative success in attracting PRMs to use the station.

The existing research is largely concerned with the accessibility of public transport in its broadest sense (e.g. $[9,19,22,37])$, rather than the accessibility of UK railway stations specifically. The bulk of the literature explores the physical and invisible barriers faced by PRMs in accessing the railway but is heavily reliant on anecdotal evidence. What is absent from the available research is empirical evidence quantifying the relationship between step-free access and railway usage by PRMs. In addition, there is a lack of research focusing on railway users and importantly, the wider benefits of railway station accessibility. As such, the value of inclusive design at railway stations currently remains unknown.

\section{Methods and data}

In order to arrive at a deeper understanding of the value of step-free access at UK railway stations, a mixed methods approach using both qualitative and quantitative research was adopted. The qualitative research involved ten semi-structured interviews with people who are experts on step-free access by virtue of experience. They were asked what they consider to be the benefits of providing step-free access. The quantitative method comprised undertaking multiple, explanatory case studies of 17 pre-selected railway stations in Buckinghamshire near Greater London in order to gain insights into the relationship between step-free access and rail usage 
by PRMs. Each of the 17 stations provides varying levels of step-free accessibility but are all operated by Chiltern Railways, allowing for the findings to be compared and contrasted.

\subsection{Qualitative approach: semi-structured interviews}

The semi-structured interviews were based on a list of predetermined questions, sufficiently structured to address specific dimensions of the benefits of step-free access but also allowed space for participants to offer new insights into the research topic. Open-ended questions are more flexible than close-ended questions, and the latter may prevent participants from expanding on the subject matter [26, 27]. This is particularly pertinent for this research as the benefits of step-free access may well be wide-ranging and thus require questions that allow for a degree of interpretation. The interviewees were asked the following three open-ended questions: (i) how does your organisation define step-free access at railway stations? (ii) what do you think the benefits of increased step-free access at railway stations would be and why? (iii) how might these benefits affect the well-being/quality of life for PRMs? By seeking insight from different interest groups (see Table 1), namely policymakers (codes A1-A4), private sector organisations (codes B1-B2), and transport disability advocacy groups (codes $\mathrm{C} 1-\mathrm{C} 4$ ), it encouraged different perspectives to emerge.

The principle of thematic analysis can be used to code and infer common messages arising from the semistructured interview data. Thematic analysis is a method used for identifying, organising, and offering insights into patterns of themes across several items of qualitative data $[3,5,30]$. The analysis primarily involves the following procedures: transcribing the interviews; familiarising oneself with the data and identifying initial codes; searching for themes; reviewing and defining themes; and generating findings. Through the process of analysis, the extraction and interpretation of findings are based on the raw data rather than researchers' own impressions. It should be noted that the identification of themes in this study was data-driven in order to reduce any analyst-oriented biases. The identified themes are linked to the theoretical literature upon completion of the analysis, and not prior to it.

\subsection{Quantitative approach: railway station usage data}

The case study sites comprise all 17 railway stations in Buckinghamshire, as shown in Fig. 2. The two Chiltern Main Line corridors serving Buckinghamshire experience high passenger volume, which has increased substantially in the last decade. As such, the 17 railway stations providing direct rail services into London/ Birmingham produce statistically reliable data by virtue of being busy commuter hubs. These stations run a mixture of local, regional and commuting services and their market catchment areas are dictated by their spatial distribution across a polycentric geography. Some stations serve dense, built-up urban towns while others serve smaller market towns or villages. The 17 railway stations vary in terms of size, number of platforms and level of accessible infrastructure. Data on accessible routes to platforms and train ramp provision were extracted from National Rail's Knowledge Base in order to grade the level of accessibility. The Knowledge Base is a database of information about facilities at all of the UK's railway stations, and includes specific information about facilities for PRMs [31]. Site visits were also undertaken to validate the grading of the stations.

Having graded the stations, the research then involved collecting entry/exit data on the number of trips made by older and disabled people using either a Senior or Disabled Persons Railcard at each of the 17 stations between January 2019 and January 2020. The Disabled Persons Railcard costs $£ 20$ per annum (Senior Railcard costs $£ 30$ per annum) in return for a $1 / 3$ discount on all off-peak travel. Senior/Disabled Persons Railcard use was calculated as a percentage of the total number of entries/exits at each station for all types of ticket. Then,

Table 1 Participant profiles

\begin{tabular}{lll}
\hline Organisation & Type of organisation and/or position held & Code \\
\hline Department for Transport & AfA Station Enhancements Portfolio Manager & A1 \\
Network Rail & AfA Programme Sponsor & Senior Transport Planner \\
Buckinghamshire Council & Accessibility and Inclusion Manager & A3 \\
Rail Delivery Group & Accessibility Lead & A4 \\
Chiltern Railways & Transport Planner & B1 \\
Project Centre & Disability Advocacy Group \\
Buckinghamshire Disability Service & Accessibility Policy Officer \\
Transport Focus & Disability Advocacy Group \\
Campaign for Level Boarding & Disability Advocacy Group & C1 \\
Transport for All & & C2 \\
\hline
\end{tabular}




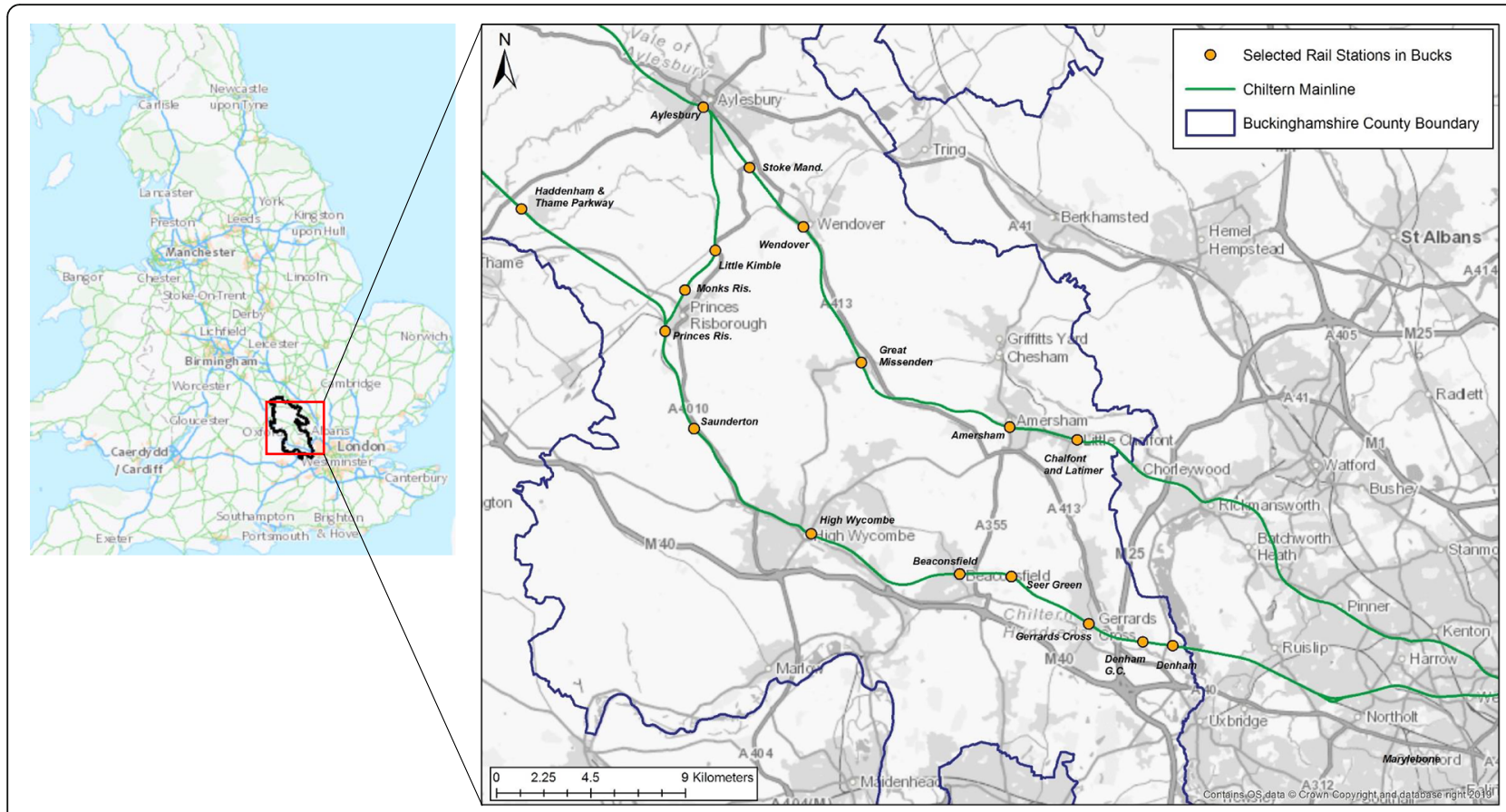

Fig. 2 Study area and case study locations (Source: Authors' elaboration)

the number of journeys made by older and disabled people as a percentage of total sales was compared against the 'level of accessibility' offered at each station via cross-tabulation. Whilst it is reasonable to infer that some older or disabled rail users may be travelling without the use of a discounted railcard, journeys made using either of these two types of railcards serve as a reliable proxy in determining the number of PRMs travelling relative to the total number of all users.

\section{Results and discussion}

The results are divided into two strands: semi-structured interview feedback from the ten stakeholder organisations who provided expert knowledge of step-free access at UK railway stations and case study analysis of Senior/ Disabled Persons Railcard usage taken from the sample of 17 different stations.

\subsection{Benefits of step-free access: findings from thematic analysis}

\subsubsection{Defining step-free access}

Two of the ten respondents stated that their organisation believed there was no single, universal definition of stepfree access, agreeing that there was more than one school of thought. This included either step-free access from street to platform or step-free access from street to train. The following excerpts illustrate the mixture of views:

"We do not have or use a standard definition, but I'm aware that there is more than one school of thought. The first is that step-free stations are those that allow the passenger to access all platforms and areas of the station without having to use steps or escalators. The second is that in order for a station to be truly step-free there needs to be level boarding (onto the train) as well." (C2, 21/07/2020)

"Step-free access is defined as from the station boundary to the point of boarding (i.e. not from platform to train)." (A4, 26/07/2020)

Whilst views on the exact definition of step-free access were mixed, there was a consensus amongst respondents regarding the philosophy driving the need for step-free access. They all interpreted 'step-free' as meaning something physical, and the removal of barriers or obstacles were frequently referenced. The responses suggested that step-free access primarily focuses on negating the challenges presented by changes in level and, where this cannot be achieved, it should be bridged by the use of ramps or lifts to avoid significant deviation or completely inaccessible routes. As many as three industrystandard definitions were provided by individual participants. One organisation's definition is specified below:

"We use the definitions provided by the Office of Rail and Road (ORR) within their guidance for rail operators to produce their Accessible Travel Plans (ATP)." (B1, 15/07/2020) 
The ORR definition categorises step-free access based on the quality and accessibility of the built environment. In this example, a station would score higher if it provided step-free access to all platforms, lower if the step-free access included steep ramps and lowest if the step-free route between platforms is greater than $400 \mathrm{~m}$, just in one direction or only to certain platforms/no platforms. Another public sector organisation used the Design Standards for Accessible Railway Stations [15] to define step-free access, and claimed that a station could only be regarded as truly step-free when it has one accessible route into the station, and to and between each platform:

"We consider a station to have proper step-free access if it has at least one accessible route into the station and to and between each platform. We do not consider stations with access to some platforms only, or both platforms with very long interchange routes outside the station, to have step-free access." (A1, 23/07/2020)

The responses suggest that there are inconsistencies in people's understandings of whether or not step-free access includes access to the train. Furthermore, stakeholders' understandings of step-free access are guided by different sources of design standards. This disparity between stakeholders may risk weakening the messaging about the importance of step-free access, to the detriment of PRMs. Therefore, according to the principle of user-centred design, both accessible routes and train access ramps should be provided. Figure 3 shows the key elements of step-free access in an inclusive railway station design.

\subsubsection{User benefits}

The responses covered a range of different themes pertaining to the benefits of step-free access. Six of the participants suggested that increasing step-free access would help to address issues relating to social and economic disadvantages currently experienced by PRMs. The importance of maximising social inclusion and economic independence was repeated by the majority of respondents:

"The benefit of step-free access, particularly that which involves level boarding, is that it gives a larger number of people an opportunity to travel independently without having to rely on the assistance of others." (C2, 21/07/2020).

"Removing these barriers will open the doors to greater social and economic independence for disabled people and greater dignity." (C1, 26/07/2020).

Building on the hypothesis that increasing step-free access would result in more disabled and older people

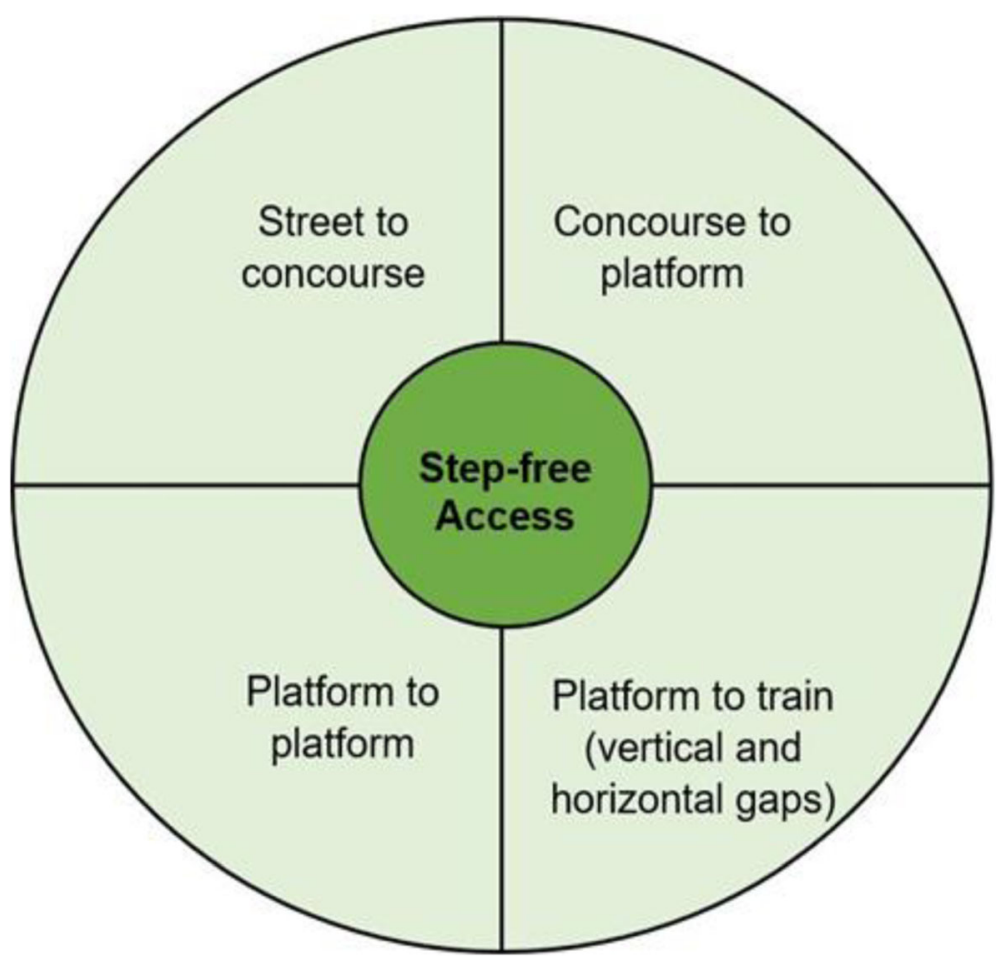

Fig. 3 Key elements of step-free access in an inclusive railway station design (Source: Authors' elaboration) 
using the UK railways, respondents also highlighted two types of secondary benefits, commercial and environmental, that could arise. These benefits are summarised in the following excerpts:

\section{"Reputational enhancement for the station facilities owner." (B1, 15/07/2020).}

"Making a station accessible generally leads to significant increases in footfall. This tends not to be abstracted from other stations, but new passengers, and therefore new fare revenue for the industry." (A1, 23/07/2020).

"This is of financial benefit to the industry as well, while the individual and step-free access would support access to employment markets." (C2, 21/07/2020).

Respondents argued that an uplift in railway passenger demand would produce environmental benefits. This could be achieved by facilitating a modal shift towards rail travel and reducing PRMs reliance on cars. In general, the respondents agreed that increasing step-free access would create a smoother and safer station experience that would benefit a multitude of passengers with and without mobility impairments. Most concurred that steps and escalators were major hotspots for slips, trips and falls at stations and that step-free access would make stations safer for all. Interestingly, six of the ten respondents acknowledged the potential benefits step-free access would have for encumbered railway users. Those travelling with bikes, luggage, children, prams or temporary injuries were all considered to benefit significantly from the installation of lifts and ramps to avoid negotiating steps. Some respondents suggested that greater step-free access would:

"Be safer for those who might not use a wheelchair or even be formally classified as 'disabled' but might nonetheless struggle with mobility (for example, elderly people using canes)." (A3, 15/07/2020).

"Help create new opportunities for those who traditionally may not have used the railway system." (A2, 27/07/2020).

\subsubsection{Well-being and quality of life}

Six of the respondents felt that increasing the independence of PRMs would improve their mental health and wellbeing. It was acknowledged that expanding travel opportunities would help reduce the risk of social isolation:

"Disabled people suffer greater levels of social isolation which has been shown to contribute significantly to negative health outcomes." (A3, 15/07/2020).
"Allowing people to choose the mode of transport that suits them best rather than simply what is accessible could lead to improvements in anxiety levels, pain and fatigue." (C2, 21/07/2020).

"Opening up rail transport could enable them to travel when they would otherwise have been stuck at home, leading to a greater inclusion in society and engagement in the community, which would impact positively on confidence and self-esteem." (B2, 18/07/2020).

One response explicitly stated that step-free access actively encourages social integration between nondisabled people and disabled people:

"Step-free access would enable a disabled person to travel into town as part of a larger group, where previously they would have had to travel separately." (A3, 15/07/2020).

Participants unanimously agreed that there would be tangible mental health benefits. Respondent A1 expanded on this idea, implying that there would also be economic benefits to HM Treasury through a:

"Reduction in the benefits bill if disabled people are able to travel to work." (A1, 23/07/2020).

Table 2 provides a summary of the key benefits of inclusive railway station design at different levels, for individuals, railway operators, and the wider society.

\subsection{Correlation analysis between step-free access and travel by PRMs}

4.2.1 Station accessibility and senior/disabled persons Railcard usage

Seventeen railway stations were analysed to ascertain whether there is a correlation between the level of accessibility and railway usage among PRMs. In this research, a station's level of accessibility, shown in Fig. 4, is defined as follows:

- Accessibility Score 2: Full, direct step-free access to all platforms with no deviation of route and train access ramp availability;

- Accessibility Score 1: Accessible routes to all platforms but no train access ramp provision;

- Accessibility Score 0: Partial, or no accessible routes to platform and no train access ramp provision.

Figure 5 shows that, out of the 17 railway stations in Buckinghamshire, the highest number of journeys made using a Senior/Disabled Persons Railcard $(106,714)$ were via High Wycombe. Little Kimble had the lowest 
Table 2 Key benefits of inclusive railway design

\begin{tabular}{|c|c|c|c|}
\hline Level & Benefits & & \\
\hline \multirow{2}{*}{$\begin{array}{l}\text { Individual (that is, } \\
\text { persons with reduced } \\
\text { mobility or PRMs) }\end{array}$} & Economic & Mental Health & Physical Health \\
\hline & $\begin{array}{l}\text { - Greater access to job opportunities, } \\
\text { especially those located near railway } \\
\text { routes } \\
\text { - Lower transport costs (e.g. lower } \\
\text { reliance on more expensive transport } \\
\text { modes like taxis) }\end{array}$ & $\begin{array}{l}\text { - Reduced levels of travel anxiety } \\
\text { - Increased self-confidence/esteem and greater } \\
\text { dignity } \\
\text { - Lower sense of social isolation (and negative health } \\
\text { outcomes like depression) } \\
\text { - More social interactions and engagement in the } \\
\text { community }\end{array}$ & $\begin{array}{l}\text { - Reduced levels of bodily } \\
\text { pain and fatigue when } \\
\text { travelling } \\
\text { - Reduction in the number } \\
\text { of people killed or } \\
\text { seriously injured by falls }\end{array}$ \\
\hline \multirow[t]{2}{*}{ Rail Operator } & Direct Revenue & Indirect Revenue & Others \\
\hline & $\begin{array}{l}\text { - New PRM users } \\
\text { - New non-PRM users due to better rail } \\
\text { travel experience }\end{array}$ & $\begin{array}{l}\text { - Secondary benefits resulting from greater vibrancy } \\
\text { of places and a thriving local economy }\end{array}$ & $\begin{array}{l}\text { - Better corporate image/ } \\
\text { reputation } \\
\text { - Fulfilment of corporate } \\
\text { social responsibility }\end{array}$ \\
\hline \multirow[t]{2}{*}{ Wider Society } & Economic & Environmental & Social \\
\hline & $\begin{array}{l}\text { - PRMs benefit from reduction in } \\
\text { unemployment } \\
\text { - Increased productivity with PRMs } \\
\text { joining the job market } \\
\text { - Reduction in government health } \\
\text { expenditure, especially in relation to } \\
\text { mental health issues among PRMs }\end{array}$ & $\begin{array}{l}\text { - Modal shift from more carbon-intensive transport } \\
\text { modes like cars and taxis to railways (e.g. improve- } \\
\text { ments in air quality, a decrease in } \mathrm{CO}_{2} \text { emissions) }\end{array}$ & $\begin{array}{l}\text { - Reduced burden on } \\
\text { families and care-givers } \\
\text { of PRMs } \\
\text { - Reduced social } \\
\text { segregation } \\
\text { - Increased harmony } \\
\text { contributing to a more } \\
\text { inclusive society }\end{array}$ \\
\hline
\end{tabular}

number of journeys made by older and disabled people (279). The lowest percentage of Senior/Disabled Persons Railcard use as a percentage of overall journeys was observed at Chalfont and Latimer (0.2\%), while the highest percentage of Senior/Disabled Persons Railcard use was found to be at Monks Risborough (9.6\%).

\subsubsection{Cross-tabulation results}

Cross tabulation was undertaken to understand more about the relationship between railway station accessibility and the percentage of those travelling with a Senior/Disabled Persons Railcard (Fig. 6). Overall, the results demonstrate that there is a positive correlation between the percentage of disabled and senior rail travellers and the

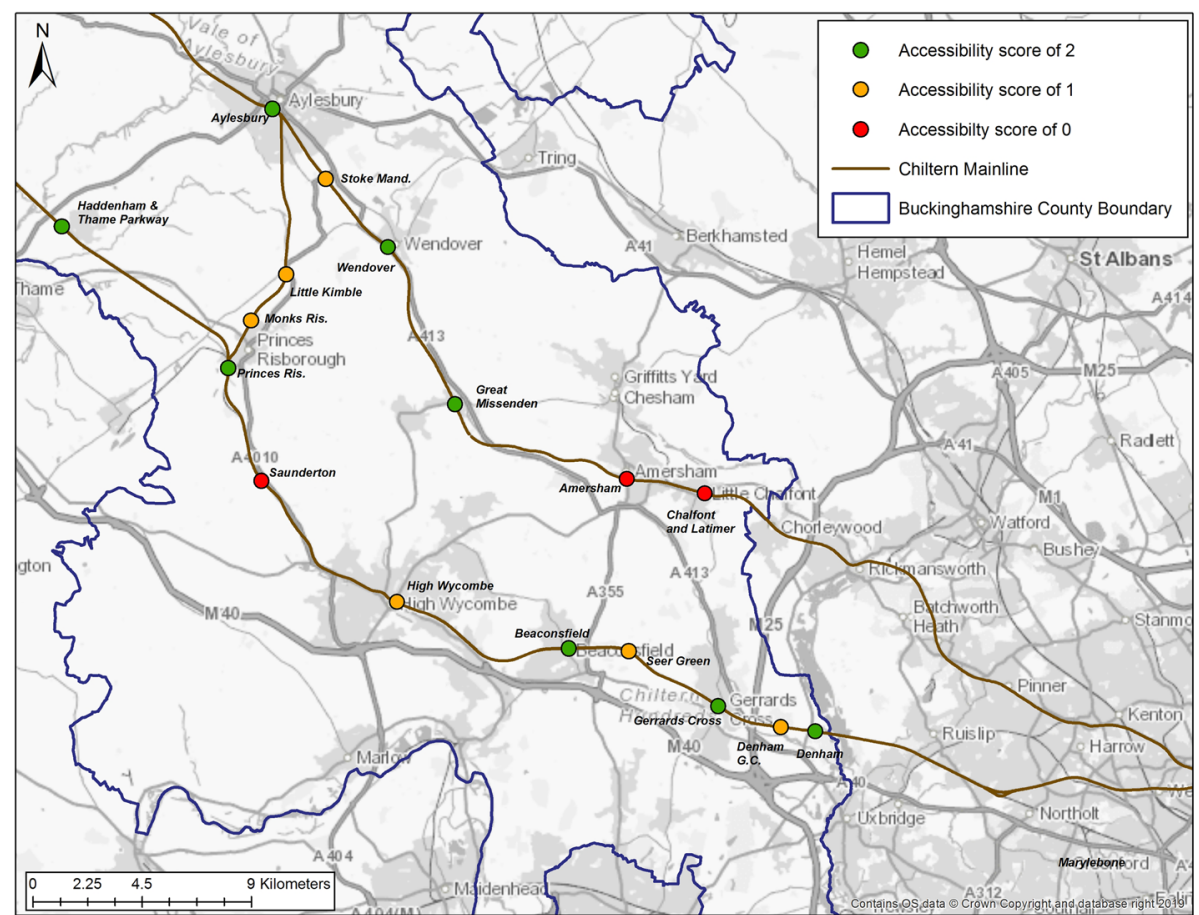

Fig. 4 Railway station accessibility grading (Source: Authors' elaboration) 


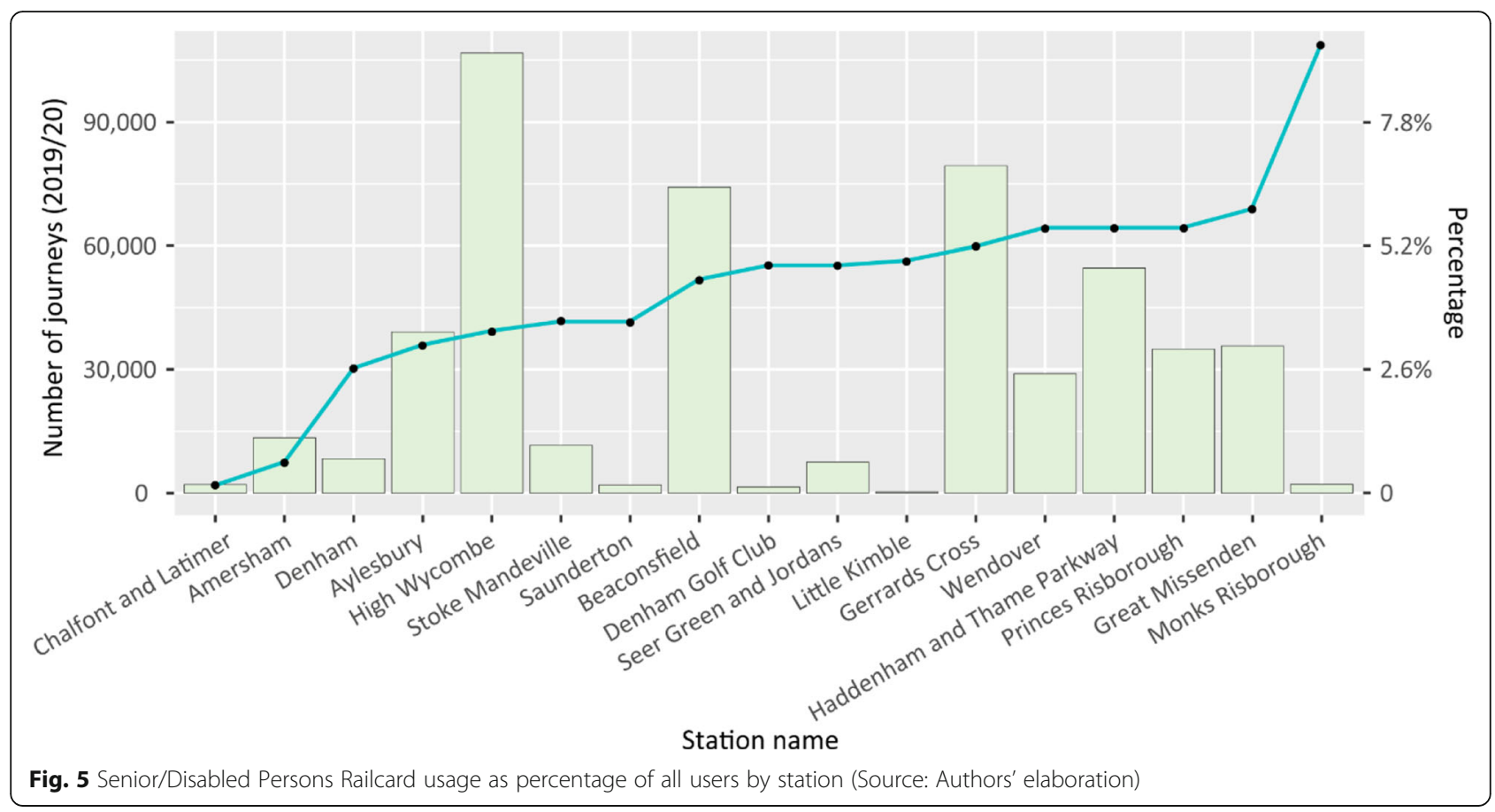

level of step-free accessibility at railway stations. Railway stations with accessibility grades of zero correspond to the two lowest percentages of Senior/Disabled Persons Railcard usage in Buckinghamshire. The three lowest graded stations - Chalfont and Latimer (0.2\%), Amersham (0.7\%) and Saunderton $(3.7 \%)$ - are found within the first and second quarter of usage levels, respectively. The interquartile range is predominantly comprised of five of the six stations that received an accessibility grade of one: High
Wycombe (3.5\%), Stoke Mandeville (3.7\%), Denham Golf Club (4.9\%), Seer Green and Jordans (4.9\%), and Little Kimble (5.0\%). Of the eight railway stations that received the highest accessibility grade of two, five of them accounted for the six highest percentiles of Senior/Disabled Persons Railcard usage: Gerrards Cross (5.3\%), Wendover (5.7\%), Haddenham and Thame Parkway (5.7\%), Princes Risborough (5.7\%), and Great Missenden (6.1\%).

\begin{tabular}{|c|c|c|c|c|}
\hline Station Name & $\begin{array}{l}\text { Journeys to or from each station } \\
\text { with Senior or Disabled Railcard }\end{array}$ & $\begin{array}{l}\text { All passenger total } \\
\text { entries/exits }\end{array}$ & $\begin{array}{l}\text { Senior or Disabled } \\
\text { Railcard as \% of total }\end{array}$ & \multirow{9}{*}{$\begin{array}{l}\text { - First quartile } \\
\quad 3.4 \%\end{array}$} \\
\hline Chalfont and Latimer & 2,099 & 865,584 & $0.2 \%$ & \\
\hline Amersham & 13,466 & $1,991,780$ & $0.7 \%$ & \\
\hline Denham & 8,375 & 307,920 & $2.7 \%$ & \\
\hline Aylesbury & 39,097 & $1,235,236$ & $3.2 \%$ & \\
\hline High Wycombe & 106,714 & $3,070,594$ & $3.5 \%$ & \\
\hline Stoke Mandeville & 11,642 & 318,244 & $3.7 \%$ & \\
\hline Saunderton & 1,984 & 53,096 & $3.7 \%$ & \\
\hline Beaconsfield & 74,203 & $1,627,052$ & $4.6 \%$ & \\
\hline Denham Golf Club & 1,486 & 30,384 & $4.9 \%$ & \multirow{5}{*}{$\begin{array}{c}\text { Median } \\
4.9 \%\end{array}$} \\
\hline Seer Green and Jordans & 7,548 & 153,314 & $4.9 \%$ & \\
\hline Little Kimble & 279 & 5,572 & $5.0 \%$ & \\
\hline Gerrards Cross & 79,396 & $1,512,018$ & $5.3 \%$ & \\
\hline Wendover & 28,935 & 511,392 & $5.7 \%$ & \\
\hline Haddenham and Thame Parkway & 54,606 & 960,972 & $5.7 \%$ & \multirow{5}{*}{$\begin{array}{c}\text {-Third quartile } \\
5.7 \%\end{array}$} \\
\hline Princes Risborough & 34,916 & 609,656 & $5.7 \%$ & \\
\hline Great Missenden & 35,692 & 582,730 & $6.1 \%$ & \\
\hline Monks Risborough & 2,123 & 22,144 & $9.6 \%$ & \\
\hline Station accessibility level 0 & Station accessibility level 1 & \multicolumn{2}{|c|}{ Station accessibility level 2} & \\
\hline
\end{tabular}


It is noteworthy that Denham (2.7\%) and Aylesbury (3.2\%) had low Senior/Disabled Persons Railcard use as a percentage of all users despite being graded as two (high) for station accessibility. This appears to be an anomaly in the data and is contrary to the pattern observed for other stations. These two stations would therefore benefit from localised research to understand the cause of this phenomenon. Similarly, Monks Risborough is an outlier in the data as it experienced the highest levels of recorded Senior/Disabled Persons Railcard use $(9.6 \%)$ despite its lack of train access ramp provision, indicated by an accessibility score of one. Future research should seek to understand other possible factors that impact railway station usage, such as the number of cardholders and the number of PRMs in the station catchment area, access/egress connections with the station, crime and safety, service reliability, and the provision of shelters, benches, and shops. In addition, there is also a need to understand whether other forms of accessible infrastructure, for example, wider ticket gates, accessible waiting rooms and toilets and accessible ticket offices, have contributed to greater rail usage by PRMs.

\subsection{Synthesis of results}

The semi-structured interviews coupled with the Senior/ Disabled Persons Railcard usage data strongly suggest that providing access to the train from the platform has as at least equal impact as providing accessible routes from the street to the platform for PRMs. The interview responses reveal a level of ambiguity as to whether the definition of step-free access should include train access. However, the Senior/Disabled Persons Railcard data shows that, in order to maximise the value of inclusive design at railway stations, both accessible routes and level access need to be provided. Evidently, the continuity offered by direct, simple to navigate step-free access with the guarantee of level access at the station is key in enabling PRMs to travel with as much certainty as possible. The research also uncovers a range of wider social, environmental and economic benefits associated with step-free access at railway stations. These wider benefits should be captured by scheme promoters and decision-makers during scheme development and appraisal of step-free access business cases.

\section{Conclusions}

This research has advanced the understanding of the value of step-free access at UK railway stations. The semi-structured interviews with ten key stakeholders and analysis of Senior/Disabled Persons Railcard usage both pin-pointed the importance of physical infrastructure, specifically accessible routes and train ramp access as being crucial in enabling those with mobility impairments to travel independently. Using data gathered from the perspectives of policymakers, railway station operators and PRMs themselves, this study found that there are a number of wider socio-economic benefits that could also be achieved by increasing step-free access. These extend beyond traditionally accepted 'social' benefits, such as increasing the independence and improving the quality of life of PRMs. Stakeholders cited secondary benefits that could be realised as a result of providing more step-free access, such as environmental benefits resulting from a modal shift from car to rail, a reduction in accidents, and an increase in the amount of railway revenue to the benefit of station operators, and benefits to central government through savings on the welfare budget. The sample of railway station data extracted from 17 stations in Buckinghamshire confirms that there is a positive correlation between step-free access and the number of PRMs making journeys to or from the station. This proves that step-free access encourages people with a disability to travel by rail, and stations that integrate accessible routes with ramp provision are most likely to experience the highest number of PRMs travelling to or from the station.

Based on the research findings, the following policy recommendations are suggested. The key recommendation is that the Government, NR and TOCs should commit to expanding and accelerating the roll-out of the AfA scheme to more railway stations in the UK. Whilst this will require an increase in capital investment in somewhat volatile conditions for the railway industry, the research indicates that any investment in step-free accessibility will return a suite of societal, economic and environmental benefits. This is due to the positive impact that higher levels of railway use have on the environment, UK GDP and improvements in PRMs' well-being. As decisions on whether to take public transport are affected by experience [32], there is a risk that without swift action to increase the number of stations that provide step-free access, a generation of travellers with reduced mobility may be dissuaded from using the railways indefinitely. This research presents an opportunity to reform and strengthen the business case and appraisal process for new investment in step-free access, ensuring that it appropriately captures both the user and non-user benefits. Finally, the government should update its Design Standards for Accessible Railway Stations to make it mandatory that any investment in step-free access is complemented by train access ramp provision, in such circumstances where level boarding cannot be accommodated. The empirical research demonstrates higher railway use among PRMs travelling at stations via both accessible routes to platforms and ramp provision. As such, it presents a clear mandate to bring a swathe of smaller and more rural stations outside of London in line with the higher number of accessible railway 
stations in the capital. However, based on crosssectional data analysis, this research only demonstrates a strong positive correlation between accessibility improvement and railway station usage. Future longitudinal studies could be carried out to quantify the specific amount of benefits that could be generated by step-free access. In addition, it has been widely acknowledged that is important to gain a multi-stakeholder perspective when appraising transport projects. The benefits of stepfree access from the perspective of PRMs are also worth investigating in future research.

\section{Acknowledgements}

Thanks very much to the editors, Professor Karst Geurs and Professor Pierluigi Coppola, and the three anonymous reviewers for their valuable comments on the initial draft of this paper.

\begin{abstract}
Authors' contributions
Antony Swift: Conceptualisation; Methodology; Formal analysis; Investigation. Long Cheng: Conceptualisation; Investigation; Writing - original draft. Becky P.Y. Loo: Conceptualisation; Supervision; Writing - review \& editing. Mengqiu Cao: Funding acquisition; Supervision; Writing - review \& editing. Frank Witlox: Funding acquisition; Writing - review \& editing. All authors read and approved the final manuscript.
\end{abstract}

\section{Funding}

The authors would like to gratefully acknowledge the support provided by the Engineering and Physical Sciences Research Council (EP/R035148/1), the National Natural Science Foundation of China (No. 71801041 and 51808392), the Sustainable Cities and Urban Environment Research Fund, School Funding from the University of Westminster, and the Estonian Research Council (PUT PRG306).

\section{Availability of data and materials}

All passenger total entries/exits data at railway stations is available on reasonable request. However, the raw data used to calculate the percentage of Senior/Disabled Persons Railcard use are not publically available due to privacy issues.

\section{Declarations}

\section{Competing interests}

The authors declare that they have no competing interests.

\section{Author details}

${ }^{1}$ England's Economic Heartland, Buckinghamshire Council, Aylesbury, UK. ${ }^{2}$ Department of Geography, Ghent University, Ghent, Belgium. ${ }^{3}$ Department of Geography, The University of Hong Kong, Hong Kong SAR, China. ${ }^{4}$ School of Architecture and Cities, University of Westminster, London, UK.

${ }^{5}$ Department of Statistics, London School of Economics and Political Science, London, UK. ${ }^{6}$ Department of Geography, University of Tartu, Tartu, Estonia.

Received: 3 February 2021 Accepted: 19 July 2021

Published online: 03 August 2021

\section{References}

1. Accessibility Action Plan (AAP) (2017). A transport system that is open to everyone Available: https:/assets.publishing.service.gov.uk/government/ uploads/system/uploads/attachment_data/file/638404/accessibility-actionplan-consultation.pdf. Accessed 9 May 2020

2. Allen, J., Muñoz, J. C., \& de Dios Ortúzar, J. (2019). Understanding public transport satisfaction: Using Maslow's hierarchy of (transit) needs. Transp Policy, 81, 75-94. https://doi.org/10.1016/j.tranpol.2019.06.005.

3. Alyavina, E., Nikitas, A., \& Njoya, E. T. (2020). Mobility as a service and sustainable travel behaviour: A thematic analysis study. Transp Res F, 73, 362-381. https://doi.org/10.1016/j.trf.2020.07.004.
4. Banister, D., \& Thurstain-Goodwin, M. (2011). Quantification of the nontransport benefits resulting from rail investment. J Transp Geogr, 19(2), 212223. https://doi.org/10.1016/j.jtrangeo.2010.05.001.

5. Braun, V., \& Clarke, V. (2006). Using thematic analysis in psychology. Qual Res Psychol, 3(2), 77-101. https://doi.org/10.1191/1478088706qp0630a.

6. Cheng, L., Chen, X., Yang, S., Cao, Z., De Vos, J., \& Witlox, F. (2019). Active travel for active ageing in China: The role of built environment. J Transp Geogr, 76, 142-152. https://doi.org/10.1016/j.jtrangeo.2019.03.010.

7. Cheng, L., Shi, K., De Vos, J., Cao, M., \& Witlox, F. (2021). Examining the spatially heterogeneous effects of the built environment on walking among older adults. Transp Policy, 100, 21-30. https://doi.org/10.1016/j.tranpol.202 0.10 .004 .

8. Cordera, R., Coppola, P., \& dell'Olio, L., Ibeas, Á. (2017). Is accessibility relevant in trip generation? Modelling the interaction between trip generation and accessibility taking into account spatial effects. Transportation, 44(6), 1577-1603. https://doi.org/10.1007/s11116-016-9715-5.

9. Cuthill, N., Cao, M., Liu, Y., Gao, X., \& Zhang, Y. (2019). The association between urban public transport infrastructure and social equity and spatial accessibility within the urban environment: An investigation of Tramlink in London. Sustainability, 11(5), 1229. https://doi.org/10.3390/su11051229.

10. Dejeammes, M. (2000). Boarding aid devices for disabled passengers on heavy rail: Evaluation of accessibility. Transp Res Rec, 1713(1), 48-55. https:// doi.org/10.3141/1713-07.

11. Department for Transport (DfT) (2018a). The inclusive transport strategy: Achieving equal access for disabled people Available: https://assets.publishing. service.gov.uk/government/uploads/system/uploads/attachment_data/file/ 729313/large-print-inclusive-transport-strategy.pdf. Accessed 8 Jan 2021.

12. Department for Transport (DfT) (2018b). Transport analysis guidance: The transport appraisal process Available: https://assets.publishing.service.gov.uk/ government/uploads/system/uploads/attachment_data/file/712965/webtagtransport-appraisal-process-may-2018.pdf. Accessed 8 Jan 2021.

13. Department for Transport (DfT) (2018c). Accessibility action plan: Summary of responses to the consultation on the draft plan Available: https://www.gov. uk/government/publications/accessibility-action-plan-consultation-summaryof-responses/accessibility-action-plan-summary-of-responses-to-the-consulta tion-on-the-draft-plan\#summary-of-responses-to-proposed-actions. Accessed 9 May 2020.

14. Department for Transport (DfT) (2019). Transport and disability. Statistical data set: Table TSGB12020 Available: https://www.gov.uk/ government/statistical-data-sets/transport-and-disability-tsgb12. Accessed 25 Apr 2020.

15. Department for Transport and Transport Scotland (2015). Design standards for accessible railway stations Available: https://assets.publishing.service.gov. uk/government/uploads/system/uploads/attachment_data/file/876528/ design-standards-accessible-stations_document.pdf. Accessed 24 May 2020.

16. Duckenfield, T. (2017). The benefits of improving access to the United Kingdom rail network via the access for all programme. Paris: International Transport Forum.

17. Flyvbjerg, B., Skamris Holm, M. K., \& Buhl, S. L. (2003). How common and how large are cost overruns in transport infrastructure projects? Transp Rev, 23(1), 71-88. https://doi.org/10.1080/01441640309904.

18. Fujiyama, T., Childs, C., Boampong, D., \& Tyler, N. (2015). Investigating ramp gradients for humps on railway platforms. Proc Institution Civil Eng Municipal Eng, 168(2), 150-160. https://doi.org/10.1680/muen.14.00011.

19. Geurs, K. T., La Paix, L., \& Van Weperen, S. (2016). A multi-modal network approach to model public transport accessibility impacts of bicycle-train integration policies. Eur Transp Res Rev, 8(4), 25. https://doi.org/10.1007/s12 544-016-0212-x.

20. Hashizume, T., Yoneda, I., Kitagawa, H., Fujisawa, S., \& Sueda, O. (2009). Accessibilities of wheelchair users to cross the gaps and steps between platforms and trains. SICE J Control Measurement Syst Integration, 2(4), 199205. https://doi.org/10.9746/jcmsi.2.199.

21. Hua, M., Chen, X., Zheng, S., Cheng, L., \& Chen, J. (2020). Estimating the parking demand of free-floating bike sharing: A journey-data-based study of Nanjing, China. J Clean Prod, 244, 118764. https://doi.org/10.1016/j.jclepro.2 019.118764 .

22. Huang, D., Gu, Y., Wang, S., Liu, Z., \& Zhang, W. (2020). A two-phase optimization model for the demand-responsive customized bus network design. Transp Res C, 111, 1-21. https://doi.org/10.1016/j.trc.2019.12.004.

23. Institution of Mechanical Engineers (IME) (2019). Mind the gap: Keeping trains and platforms level is a 'complex' issue Available: https://www.imeche. 
org/news/news-article/mind-the-gap-keeping-trains-and-platforms-level-is-a'complex'-issue. Accessed 23 May 2020.

24. Jones, T., \& Jain, J. (2006). Examining the experiences of sight-impaired travellers: The next station stop? Br J Vis Impair, 24(3), 141-144. https://doi. org/10.1177/0264619606066198.

25. Karekla, X., Fujiyama, T., \& Tyler, N. (2011). Evaluating accessibility enhancements to public transport including indirect as well as direct benefits. Res Transp Bus Manag, 2, 92-100. https://doi.org/10.1016/.j.tbm.2 011.06.010.

26. Low, W. Y., Cao, M., De Vos, J., \& Hickman, R. (2020). The journey experience of visually impaired people on public transport in London. Transp Policy, 97 , 137-148. https://doi.org/10.1016/j.tranpol.2020.07.018.

27. Lyu, Y., Cao, M., Zhang, Y., Yang, T., \& Shi, C. (2020). Investigating users' perspectives on the development of bike-sharing in Shanghai. Res Transp Bus Manag, 100543. https://doi.org/10.1016/..rtbm.2020.100543.

28. National Travel Survey (NTS) (2019). Travel by mobility status and main mode or mode Available: https://www.gov.uk/government/statistical-da ta-sets/nts08-availability-and-distance-from-key-local-services. Accessed 19 May 2020.

29. Network Rail (NR) (2020). Network rail access for all - Improving accessibility at railway stations nationwide Available: https://www.networkrail.co.uk/ communities/passengers/station-improvements/access-for-all-improving-a ccessibility-at-railway-stations-nationwide. Accessed 8 Jan 2021.

30. Nikitas, A., Wang, J. Y., \& Knamiller, C. (2019). Exploring parental perceptions about school travel and walking school buses: A thematic analysis approach. Transp Res A, 124, 468-487.

31. NRE (2020). National Rail Knowledgebase Available: https://www.nationalrail. co.uk/56910.aspx. Accessed 11 Aug 2020.

32. Park, J., \& Chowdhury, S. (2018). Investigating the barriers in a typical journey by public transport users with disabilities. J Transp Health, 10, 361368. https://doi.org/10.1016/j.jth.2018.05.008.

33. Rail Safety and Standards Board (RSSB) (2014). Guidance on Interface between station platforms, track and trains Available: https://catalogues.rssb.co.uk/rgs/ standards/GIGN7616\%201ss\%202.pdf. Accessed 24 May 2020.

34. Schmöcker, J. D., Quddus, M. A., Noland, R. B., \& Bell, M. G. (2008). Mode choice of older and disabled people: A case study of shopping trips in London. J Transp Geogr, 16(4), 257-267. https://doi.org/10.1016/j.jtrangeo.2 007.07.002.

35. Šimeček, M., Gabrhel, V., Tögel, M., \& Lazor, M. (2018). Travel behaviour of seniors in Eastern Europe: A comparative study of Brno and Bratislava. Eur Transp Res Rev, 10(1), 16. https://doi.org/10.1007/s12544-018-0286-8.

36. Spurling, D., Spurling, J., \& Cao, M. (2019). Transport economics matters: Applying economic principles to transportation in Great Britain. Boca Raton: Brown Walker Press.

37. Tiznado-Aitken, I., Lucas, K., Muñoz, J. C., \& Hurtubia, R. (2020). Understanding accessibility through public transport users' experiences: A mixed methods approach. J Transp Geogr, 88, 102857. https://doi.org/10.101 6/j.jtrangeo.2020.102857.

38. Van Hagen, M., \& Van der Made, J. (2017). From customer insights to new services. In proceedings of the 45th European transport conference, Barcelona, Spain.

39. Venter, C. (2009). Transport expenditure of elderly, disabled, and poor travellers: The cost of being mobile. Presented at the Transportation Research Board $88^{\text {th }}$ annual meeting, Washington, D.C., United States.

\section{Publisher's Note}

Springer Nature remains neutral with regard to jurisdictional claims in published maps and institutional affiliations.

\section{Submit your manuscript to a SpringerOpen ${ }^{\circ}$ journal and benefit from:}

- Convenient online submission

- Rigorous peer review

- Open access: articles freely available online

High visibility within the field

- Retaining the copyright to your article

Submit your next manuscript at $\boldsymbol{\nabla}$ springeropen.com 